\title{
Follow Me, What's the Harm? Considerations of Catfishing and Utilizing Fake Online Personas on Social Media
}

\author{
Lauren Reichart Smith and Kenny D. Smith \\ Indiana University \\ Matthew Blazka \\ Indiana State University
}

\begin{abstract}
This essay centers on the concepts of catfishing and online impersonation. Utilizing the Manti Te'o catfishing hoax and the Texas Tech football coaching staff's admittance of using fake profiles on social media to follow their players as a basis, this piece will examine past instances of athletes and catfishing and the connection between collegiate athletics and catfishing. Past legal incidents that focus specifically on catfishing, as well as specific laws that could have ramifications on catfishing and fake online personas will be discussed. Finally, the legal considerations that may have a potential effect on the various communication elements within social media platforms will be explored. Recommendations for future research will also be presented.
\end{abstract}

Keywords: social media; athletes; catfishing

On September 15, 2012, Notre Dame University linebacker Manti Te'o recorded 12 tackles to help lead Notre Dame to an upset win over Michigan State University. What made this particular story so compelling was not the athletic dominance of a collegiate football player, but that his performance came only hours after learning of the deaths of both his grandmother and his girlfriend, who died on the same day. The story of Manti Te'o and Lennay Kekua, his girlfriend, resonated across the nation, both in the world of sports and outside it. The Notre Dame community came together over the death of Kekua, raising over $\$ 4,000$ for the Leukemia and Lymphoma Society (Chronicle of Philanthropy, 2013). The story of the romance between Te'o and Kekua followed him through his Heisman campaign, where he finished second in the voting, to Notre Dame's first appearance in the BCS national championship game. Te'o was heralded across media outlets after saying the death of Kekua inspired him to play better (ESPN.com, 2013).

L.R. Smith and K.D. Smith are with the Media School, Indiana University, Bloomington. M. Blazka is with the Dept. of Kinesiology, Recreation, and Sport, Indiana State University, Terre Haute. Address author correspondence to Lauren Smith at LS35@iu.edu 
Though Te'o approached the Notre Dame coaching staff in December, the truth of the story didn't become public until mid-January of 2013: Te'o had fallen victim to a catfishing scam. Kekua wasn't dead. She never existed. Notre Dame subsequently investigated and cleared Te'o of any wrongdoing in the matter (Gutman \& Tienabeso, 2013).

The Te'o girlfriend hoax was not the first time the term catfishing had been brought to the forefront of a national conversation (Brady \& George, 2013). The Te' o hoax was also not the first time an athlete had fallen victim to catfishing. The term catfishing is defined as a deceptive activity involving the creation of a fake online profile for deceptive purposes (Harris, 2013). In other words, Internet and social media users are using pretend personas through the use of online profiles (Nolan, 2015). A 2010 movie titled Catfish lead to an MTV reality television series, Catfish: The Show. Both the movie and television show centered on the lies associated with online dating and how different individuals fell prey to Internet scams. The Te'o hoax was the first time catfishing was linked to the sports world on a national scale. The Te'o girlfriend hoax was also not a singular event; other stories have emerged not only of athletes being duped by fake personas online but also of athletes themselves engaging in catfishing scams. In August 2016, Texas Tech University came under fire when head coach Kliff Kingsbury said the coaching staff sets up fake social media accounts, all as cute girls, to monitor player activity on social media, but not with the goal of catfishing players (Kercheval, 2016).

The notion of coaches purposely creating fake social media accounts to follow players raises several interesting legal, regulatory, and ethical questions about communication. This essay seeks to examine past instances of fake accounts and the legal issues that have arisen, and debate the implications of fake social media accounts and athletes going forward.

\section{Catfishing and Social Media}

The use of social media has become a cultural norm; however, there are issues relating to the realness of users. In fact, Twitter, the second-largest social media platform, has admitted as recently as 2013 that five percent of all accounts are fake (D’Onfro, 2013). In addition, 83.09 million accounts on Facebook have been deemed as fake (Fire, Kagan, Elyashar, \& Elovici, 2014). Fake accounts have contributed to users either catfishing or being catfished. For example, users can use Twitter to send a direct message to another user that will not be seen by the rest of the Twitter community, which could provide an opportunity to be catfished. As mentioned above, catfishing has made inroads into the sport world surrounding the Manti Te'o case in 2013. There have been numerous incidents over the last half decade of athletes being catfished.

Social media has become a major part of one's daily experience. According to Safko and Brake (2009), social media encompasses interactions between people online - all the ways they participate in and share information, knowledge, and opinions while using web-based applications to communicate. Social community channels can be described as a way for users with common interest to participate in exchanges online (Tuten \& Solomon, 2013). In addition, these sites can be defined as collaborative projects (e.g., Wikipedia), blogs, content communities (e.g., YouTube), social networking sites (e.g., Facebook), virtual gaming world 
(e.g., massively multiplayer online role-playing game), and virtual social worlds (Second Life application) (Kaplan \& Haenlein, 2010). The social networking sites include the largest social media platforms Facebook and Twitter. On both Facebook and Twitter, users can create a profile with a picture of their liking, and create their own online self-presentation. In addition, users are able to create an online identity that could be another persona all together. Within Facebook and Twitter, there is an element of interaction that can be privatized between users, both real and through fake personas.

\section{Social Media Education}

Within sport, research has been developing between social media policy development and athletes, specifically athletes who are in college. Social media policies have been created as part of the student-athlete handbooks at various institutions (Sanderson, Snyder, Hull, \& Gramlich, 2015) Sanderson (2011) examined social media policies at 159 Division I institutions. His findings noted that policies were more restrictive than actually providing any real social media training. Sanderson, Snyder, et al. (2015) took the next step and examined social media policies at schools across all three NCAA divisions (I, II, and III). Similar findings were echoed with social media policies being most restrictive. In addition, Sanderson, Snyder, et al. (2015) found that student-athletes were being given mixed messages about the content they were displaying. Similarly, Sanderson and Browning (2013) interviewed 20 student-athletes at the NCAA Division I level about the messages they were receiving from their athletic departments. Results noted that there was (non)training, surveillance and monitoring, and reactive training. Social media education was generally found to occur after an infraction or as a result of not fully understanding the policy. Sanderson and Browning (2013) encouraged athletic departments to be more proactive and define their boundaries rather than being reactive. While research on social media training and policies has highlighted the negative aspects, Sanderson, Browning, and Schmittel (2015) noted there should be a blend of both positive and negative effects of social media, and both should be included in social media training. With more development in training, athletes would be better suited to understand the proper use of social media (Sanderson, Snyder, et al., 2015) and thus avoid the pitfalls that affect users such as Te'o. Though Internet stalking in general is not a new phenomenon, the nature of sport and the celebrity status that tends to attach to an athlete may make athletes more vulnerable to catfishing scams.

\section{Catfished Athletes}

Since 2011, there have been multiple instances of athletes, both at the collegiate and professional levels, being involved in catfishing scams. Table 1 outlines each incident in full.

In 2011, Ikemefuna Chinedum "IK" Enemkpali, a football player for Louisiana Tech University, was caught in a catfishing situation on Facebook, and later told police he thought he was being "set up" for a possible robbery, and received threatening text messages (Lavigne, 2015; Reimer, 2015). According to NFL sources, the incident led to teams either taking him off their draft board or being "dissuaded" from drafting Enemkpali. 


\section{Table 1 Incidences of Athletes and Catfishing}

\begin{tabular}{|c|c|c|}
\hline Player(s) & Year & Explanation \\
\hline $\begin{array}{l}\text { Ikemefuna } \\
\text { Chinedum "IK" } \\
\text { Enemkpali }\end{array}$ & 2011 & $\begin{array}{l}\text { Louisiana Tech football player. Exchanged Facebook messages with } \\
\text { "Missy Lee." Told police that he believed he was being set up for a } \\
\text { robbery and that he had received text messages from "Missy Lee" } \\
\text { threatening to sue him for assault. Police linked Ketryn Anderson to } \\
\text { the "Missy Lee" profile. Anderson eventually admitted to the Facebook } \\
\text { profile and to making phone calls as the father of "Missy Lee." }\end{array}$ \\
\hline
\end{tabular}

Manti Te'o

Four Washington

Redskins players

Pat McAfee

Chris "Birdman"

Andersen

University of

Michigan

Three Australian

Football League players

Texas Tech

University
2013 Notre Dame football player. Exchanged Twitter messages with "Lennay Kekua," until he was told Kekua died. Story was heralded as inspirational until it came out as a hoax.

2013 Four players engaged in messaging "Sidney Ackerman" (RedRidnH00d) on Twitter. The profile photo used for the account was of C.J. Miles, an Internet adult entertainer. The account came to light as fake, and just before the NFL going public with the story, the account was removed and the "Sidney Ackerman" Facebook page was deleted. The account was also followed by 22 verified NFL players and 6 verified NBA players on Twitter.

2013 Indianapolis Colts player. Received messages on Twitter from "Abigail Johnson" in Houston. She continued to send messages over the course of a couple days, and McAfee eventually got a message saying, "I wish guys in Texas were like you." According to McAfee, these tweets tricked him and he followed her back, which then led her to send a direct message stating, "I thought you were never gonna (sic) notice me." He later would watch Catfish, where the blonde whom he may have been talking to was "Abigail Johnson."

2013 NBA player. Involved in a cyber identity theft scheme by a woman in Canada. The woman allegedly hacked Andersen's e-mail, phone, social media outlets, bank records, and video game console to establish a relationship with another woman. The woman also posed as other people, including impersonating other NBA players. She was arrested for personation, extortion, and utter threats.

2013 Admitted to hiring Hired consulting firms to catfish their own student-athletes. One of the consulting firms, 180 Communications, used an attractive female to contact the athletes. Some of the athletes replied to the unnamed woman's messages. After several weeks, the woman turned over the comments that were sent to her and the student-athlete names who sent the messages.

2016 Serial catfisher posed as an Australian model and engaged in interactions with players. In addition, one of the players sent provocative photos to a woman he met online. That woman was actually a man who sent the provocative photos to an X-rated site along with the player's name. AFL policy prohibits its players from sending pornographic images through social media (Eddie, 2016).

2016 Kliff Kingsbury, Texas Tech Head football coach, admits to creating fake "cute girl" accounts to monitor student-athletes. 
During the same time frame of the Manti Te'o saga, at least four Washington Redskins players were part of a catfishing hoax (Darlington, 2013), which included the fake account being followed by various NFL and NBA players. In addition, Pat McAfee of the Indianapolis Colts, told his firsthand account of being catfished on Twitter in the same time frame as the Te'o story.

In an odd but different type of catfishing, former NBA basketball player Chris "Birdman" Andersen was involved in a cyber identity theft scheme ran by a woman in Canada (DelVecchio, 2013). A 2016 incident involving a serial catfisher posing as an Australian model led to at least three Australian Football League (AFL) players being scammed, including one player sending provocative photos (Coster, 2016). AFL policy prohibits its players from sending pornographic images through social media (Eddie, 2016). Like the AFL, collegiate programs across the country have instituted social media policies to protect their athletes.

\section{College Athletic Programs}

To provide more clarity and understanding to their student-athletes, some universities have used their own form of catfishing. In 2013, the University of Michigan used Facebook and Twitter to allegedly catfish their student-athletes to teach them the pitfalls of social media. The school hired two consulting firms to help monitor their student-athletes' activity on social media. The University of Michigan claims that they were not catfishing, but simply teaching their athletes the dangers of social media (Schroeder, 2013). Similarly, in 2016, Texas Tech University's head football coach, Kliff Kingsbury, admitted that he indeed catfished his players (Parker, 2016). During a radio interview, Kingsbury stated, "We have fake accounts with cute girls that they add right now, so we can see what's going on and who's tweeting . . . . Those are heavily monitored for sure." Kingsbury said that he thought the players know the athletic department is undertaking such an activity, but they have difficulty not accepting a friend request from a cute girl. He said it is almost an "automatic follow" (Parker, 2016). Kingsbury noted that the social media posts are collected and used to show the athletes potentially harmful and damaging posts.

\section{Legal Considerations of Catfishing}

From MTV to Manti Te'o, the concept of catfishing has found its way into the courtroom. The first such mention stemmed from a case brought by two university students against Ball State. In Zimmerman v. Ball State et al. (2013), the plaintiffs sued on due process and First Amendment grounds after they were suspended for a year following student conduct violations. Judge Jane Magnus-Stinson, in finding for the university over the students, used Urban Dictionary, a crowd-sourced dictionary of slang, to define catfishing. While the origin of the judge's definition might raise a few eyebrows, the idea continues to be raised in legal settings.

\section{Online Impersonation Legislation}

Some states, including California and Louisiana, have passed legislation in recent years to address online impersonations. New York, Pennsylvania, and others have 
bills pending. Texas emerged as one of those states with a law on the books. The 2009 legislation is found in the Texas Penal Code under Title 7 (Offenses Against Property), Chapter 33 (Computer Crimes), which discusses online impersonations. The law considers it a felony if a name or persona of a third party is used "with the intent to harm, defraud, intimidate, or threaten any person." It would be a misdemeanor to send a mediated message referencing a name or other identifying information belonging to a third party without consent, with the intent to mislead or defraud. Early in 2016 a state judge found Texas Penal Code $\S 33.07$ to be overly broad and unconstitutional in a case involving a man arrested for publishing compromising photographs of his ex-wife on a social media platform (Witherspoon, 2016).

As online impersonations are a relatively new concept legally speaking, there are not always specific laws in place. Furthermore, with Section 33.07 of the Texas Penal Code under fire, it would be wise to consider whether existing laws, on either a state or federal level, might be positioned to provide relief. Each case being different, and the specific laws as written varying by jurisdiction, some of these legal theories might be seen as applying in the general sense.

\section{Legal Claims for Online Impersonation}

Fraud. Fraud claims are premised on the fact that a person knowingly materially represented himself or herself, and a third party then relied on this misrepresentation (Podgor, 1999). The first individual, knowing it was a false representation, intended a third party to rely on it. Some manner of injury to the second or third party must be endured. Material misrepresentation might not be difficult to demonstrate in a relationship created by online impersonation, but injury may be more difficult to prove. Legal success might be predicated on whether the impersonation was used to obtain money or other items of credit from the victim.

Emotional Distress. If there was no financial or other valuable gain involved, a victim may consider a claim for intentional infliction of emotional distress. Generally, the victim must demonstrate that the impersonator's behavior resulted in more than severe emotional distress in the victim. That would require showing psychological damage owing to the impersonator's conduct. Simply following a player with an attractive avatar likely would not meet this condition. If we return to Manti Teo's case, where someone created a romantic partner who was then said to have died, the argument of emotional distress might be more successful. Several states-California (Dillon v. Legg, 1968), Illinois (Rickey v. Chicago Transit Authority, 1981), and North Carolina (Young v. Western Union Tel. Co., 1890) among them-have recognized the concept of negligent infliction of emotional distress. California's Dillon case has become a benchmark of this type of widespread tort. In Dillon, the plaintiff claimed "shock and injury to her nervous system, which caused her great physical and mental pain and suffering" after being near, and witnessing, a collision that claimed her daughter's life. That court decided with the plaintiff, saying relief should be granted in such a case where foreseeability, or a defendant's "due care," was possible. This delves into an emotional harm with the liability following if that emotional harm manifests physically. Severe emotional distress alone would not suffice. More than 30 
states, including Texas, have adopted the Dillon v. Legg opinion as a benchmark (Kircher, 2007).

Misappropriation of Likeness. In a circumstance like the one under consideration at Texas Tech, there is the matter of a misappropriation of likeness. The "cute girl" whose picture (or other social media content) is being used may conceivably have a potential claim as a tort. The Digital Media Law Project suggests that, typically, this would require demonstrating that a protected attribute, such as a name or a likeness, has been used ("Using the Name," 2014). The second test would involve demonstrating the likeness was used for commercial or exploitive purposes. The third test is consent: a plaintiff must demonstrate that she did not give permission for the use.

Furthermore, the issue of consent brings to mind a common question about photographic works. In a strict legal sense, a question that should be asked each time a photograph is intended for a social media use is a matter of basic copyright. Who owns that photograph? In the United States photographs are protected by copyright from the moment of creation. Photographers have the exclusive right to reproduce their photographs, unless they grant or sell those rights to others.

Depending on the specific circumstances of the case, a claim for stalking or harassment may also be available for either the athlete as victim or the person whose persona has been misappropriated. Given challenges to other legislation and the Texas Penal Code $\S 42.07$ harassment law, Beagle (2011) suggested that Texas' stalking and harassment law is currently uncertain. Scott v. Texas (2010) is the case Beagle points to here, where an appeals court found the law's language "unconstitutionally vague."

The "cute girl" in the photograph conceivably could argue defamation if a perpetrator is making false statements against her reputation. Franklin and Bussel (1984) wrote that after New York Times Co. v. Sullivan (1964) and Gertz v. Robert Welch, Inc. (1974) the legal burdens have shifted. Defamation, they suggested, involves not only what a reader understood but also whether the writer possessed an awareness of the defamatory meaning at the moment. Franklin and Bussel saw this as a "danger to free expression and the danger to the judiciary of trying to resolve the unresolvable."

Invasion of Privacy. Another legal theory that might be applied would be that of invasion of privacy. Judicially, privacy is a freedom from the unwarranted appropriation or exploitation of one's personality, the publicizing of one's private affairs, or the wrongful intrusion into one's private activities in such manner as to outrage or cause mental suffering, shame, or humiliation. That definition is applied in Texas' Billings v. Atkinson (1973) case, which had to do with intrusion into private activities by way of tapping phone lines. Topheavy Studios, Inc. v. Doe (2005) dealt specifically with images of a young woman used within, and in the marketing for, a video game. She had signed a marketing release, which the video game maker argued was consent, but the consent was voidable, Doe claimed, because she was a minor at the time. The Texas Court of Appeals upheld the previous court's finding of an injunction against the game's further distribution. Other cases to consider include Wood v. Hustler, Inc. (1984), which involved the publication of a stolen photograph under a forged consent form, and Braun v. Flynt (1984), where a jury found a magazine's publication of a photograph created a false light of the plaintiff. 
FERPA. Finally, and perhaps most notably, there is the issue of FERPA to consider. Under the Family Education Rights and Privacy Act (20 U.S.C. § 1232g) students at Texas Tech have the right to request, inspect, and review the university's records. If the university did not produce this information-meaning, conceivably, the false identities being used to monitor the specific student-athlete-it would risk running afoul of the law, and risk losing federal funding.

Each of these possibilities have their own unique defenses, of course. The coach's admission would seem to be problematic in a legal sense, however. As noted previously, Kingsbury and Texas Tech might not be alone in this practice. Beyond the legal concerns, there are also many obvious ethical considerations as well.

\section{Implications on Communication}

Fake accounts on social media have run the gamut from amusing and playful to harmful and deceptive. Individuals have faced fines for deceptive Twitter accounts that have launched police investigations (Morrison, 2014). Based on the previously outlined legal cases and issues that have arisen, the distinction needs to be made between catfishing and simply impersonating someone online. When a social media user engages in catfishing, the end result is with an intent to dupe an individual. The end motive may be different (e.g., embarrass, harass, commit a criminal act), but the intent of deception remains constant. The creation of a fake online persona may have different motivations behind it, and duplicity may not be one of the reasons. There are currently many fake accounts on Twitter, such as a parody of ESPN's highlight show @NotSportsCenter and Fake Peyton Manning (@FakePManning), that seem to be solely used for the purposes of humor and entertainment. To date, no individual has reported being deceived by these types of fake accounts.

When considering the potential legal implications for the communication medium or the process occurring behind catfishing or creating a fake online account, the intent of the person doing the impersonating seems to be the center of the issue. When looking specifically at the Texas Tech case, Kingsbury admitted that the coaching staff had created fake accounts to friend, follow, and monitor player activity, but he also stated that the accounts are used for education, and not with the intent to catfish or deceive. Given the generally open nature of Twitter, anything a "cute girl" could see from the star running back's account would also be visible to a coach or staff member who is also following the player. It is reasonable to wonder, then, what members of the Texas Tech athletic department would otherwise gain from a basic follow of a fake, or impersonated, individual. With that in mind, it would be easy to speculate about how that information could be gained through the guise of fake fans. Most collegiate athletes are aware that their social media accounts are monitored, either by their coaching staff or a designated university office. Kingsbury's admission that the Texas Tech coaching staff creates fake profiles of cute girls, because a cute girl is an automatic follow, is problematic on several fronts.

The behavior of creating fake profiles may highlight that the coaches and staff do not truly understand the nature of social media. As noted previously, past research has examined social media policies and practices at the collegiate level; however, that literature primarily focuses on the student-athlete. Findings from such research include specific instruction on how to use social media, explicitly clear 
policies on social media use, more student education on the present social media policies in place, and more proactive staff roles in athlete social media account monitoring (Sanderson, 2011; Sanderson \& Browning, 2013; Sanderson, Snyder, et al., 2015). Noting that student-athletes tend to not be informed on social media policies, as well as not understand the implications of privacy protections and free speech rights, O'Connor, Schmidt, and Drouin (2016) suggested more education on both areas was necessary. Sanderson, Snyder, et al. (2015) noted that research on policies is limited due to regulation being a new phenomenon in collegiate athletics; currently, the NCAA faces its own challenges in creating policies, tending to leave the implementation up to the individual school (Epstein, 2012). Lacking from the literature is any significant discussion on what specific education and policies coaches are adhering to. Coaches and staff should be held accountable for their actions on social media and should strive to act as role models while educating athletes on proper usage of social media (DiVeronica, 2014, Epstein, 2012).

On platforms such as Twitter and Instagram, as long as the athlete has a publicly available profile, they do not have to grant a reciprocal follow in order for followers to see their content. If the athlete's profile is private, then they do need to accept the follow request, but again, they do not have to follow the individual back. Facebook would be an exception, as accepting a friend request grants both parties access to the other's profile. Similarly, Kingsbury may have been speaking of Twitter as a proxy for all social media, which again would highlight a troubling lack of knowledge of social media platforms.

The final front that is problematic deals with the question of why create a fake account. If a follow by a coach yields the same information from the athlete that a follow from a fake cute girl would, then what is the motivation behind the fake account? And what are the coaches doing with these fake accounts that they are not stating publicly? Are they using these accounts to try and draw athletes out through direct or private messages, asking to meet up, share X-rated photos, or other activity that violates player codes of conduct? While likely a stretch, not knowing the details behind the action of the coaches could potentially raise questions of illegal searches of student-athlete social media accounts, and potential Fourth Amendment violations Again, this scenario may be both unlikely and impossible to quantify (i.e., what makes a search of a public account illegal), but this is another avenue athletic departments should be aware of that could raise legal concerns. In this situation, or any situation where a coach or university staff member is using a fake account to monitor a player, not only do the actions and intent of the coach or staff member need to be considered, but the effect on the athlete also has to be taken into consideration. If the athlete is aware fake "cute girls" are following them, do they feel a level of intimidation? Do these fake accounts threaten them in any sense? Is there a level of defrauding going on? Further, if these accounts are trying to draw them out in some manner, do they feel as though they are being harmed?

If malicious intent is removed from the motivation to create a fake online persona, then there are still legal ramifications that could arise that should be considered by users. The primary issue would center on copyright infringement. Any time a social media user posts a photo that is not owned by him or her, questions of copyright enter the equation. In any of the previously mentioned catfishing accounts, the individual women whose images were used without their knowledge or permission could seek damages from their likeness being used on a fake Twitter 
account. If the photograph in question came from a professional photographer (e.g., an Associated Press photographer), the photographer owns the rights to the photo and could seek damages for the unauthorized replication. If the image was produced by a member of the working media, the rights to the photograph might then belong to their company, which would conceivably have the same complaint.

In the instances of the Manti Te'o catfish and the Texas Tech coaches creating fake accounts, both of these are dependent on photographs of young women. The multiple photographs of Kekua that were used in the fake account and later posted across national news outlets belonged to a woman in Torrance, California. Though most of the photographs came from her private Facebook and Instagram accounts, the woman confirmed that one photograph was never posted on social media, but had been specifically requested from her (Burke \& Dickey, 2013). In the other outlined instances, very little information is given as to where the fake profile pictures came from. Only in the cases of the Washington Redskins players and the University of Michigan tactics does the reader know where the photographs came from. In one case the image of an Internet adult entertainer was used, and though the entertainer did not make a statement on whether she gave her permission for the photograph to be used in the scheme, one would likely be safe to assume she did not. In the information provided by the consulting firm hired by the University of Michigan, one of the employees of the firm used her own image in the accounts, which creates a different, yet still dishonest, scenario.

Though it was not stated by the Texas Tech coaches where the photographs were obtained, one is left to wonder if the coaches have contacted these individual women and obtained their permission to use their photographs for the purpose of creating duplicitous accounts. Thus, not only the coaches, but anyone who repurposes a photograph for a fake account without the photograph owner's permission risks running afoul of copyright law. The University of Michigan escaped that issue in at least one instance with the hired consulting firm. Though the actions of the other firms the university hired were not spelled out, there is a difference in an employee using her own image in the fake profile, versus coaches (or other individuals) using images of individuals without permission. Diane O'Meara, the actual face of Lennay Kekua, noted that she was horrified to discover her images were being used for this profile and that she had been tricked into providing her own images. She also stated that Ronaiah Tuiasosopo, the operator of the fake Kekua account, had been stealing images of her from her social media accounts for five years (Abrotsky, 2013). As noted previously, coaches and athletic staff should act in the capacity of a role model for student-athletes. If their behavior includes stealing photographs from unsuspecting individuals to use in schemes, no matter the intent or reasoning behind the scheme, then they are both breaking the law and potentially inflicting some sort of negative emotion on the individual, should the individual find out their image was used. O'Meara gained unwanted national attention in the Te'o story; a similar situation could arise for another woman should the Texas Tech coaches not be acting in a professional and appropriate manner. Breaking copyright law and potentially causing distress to an individual should not be behaviors that coaches or staff interacting with student-athletes should be modeling.

The medium is also not without potential culpability in these scenarios. Though Twitter will act quickly when asked to remove a fake profile, and has recently shown a willingness to ban an account that used a gif during the Olympics 
after the International Olympic Committee (IOC) put out a "no gif" rule (Weber, 2016), the fact remains that social media platforms may not be doing enough to control fake online accounts. Further, the platform cannot know the intent behind every account created. To expect them to be proactive in banning fake accounts is unrealistic. However, the extent to which the platforms punish individuals who create fake accounts is unknown. Legally, what actions should they take, and what actions are they allowed to take? In the previously mentioned gif of Olympic footage, the suspended account was unsuspended after the story told by the account user seemed to gain enough steam and traction for other individuals to side with the account holder over Twitter's rules and the IOC's ban. This suggests that the platforms themselves are, at times, still grappling with how to proceed in the various circumstances their users create.

\section{Conclusion}

It would be simple to look at the Manti Te'o incident and conclude that it was a unique and isolated circumstance, but as demonstrated through the examples in this paper, there have been several instances of athletes both being catfished and acting as a catfish. While the deceptive motive behind catfishing raises both legal and ethical considerations, the concept and act of catfishing also ties in to the idea of the creation and use of fake online personas. Though the motives behind catfishing and fake personas may be different, both come with legal considerations tied to various parts of the acts.

For communication scholars, the issues to be questioned and solved do not fall along the legalities of the matter; rather, researchers should begin to question the motivations behind utilizing social media platforms in a duplicitous manner, as well as the potential effects of this practice. Examinations on effects could range from credibility of coaching staffs, effects on athletes, and effects on the attitudes of the fan base of a particular athlete or team professional staff. Fan base research could explore the potential changes in attitude if fans know the coaching staff freely admits to using fake accounts and toward athletes who are either catfished or who engage in catfishing behaviors.

From a sport management perspective, it has been noted that student-athletes are not being properly trained. Student-athletes could be educated to be more self-aware on social media in the digital space. Providing this type of education along with their social media education can help athletes understand their status as a student-athletes, especially those on large college campuses. This type of training could also help coaches and athletic departments develop their social media education for athletes. Developing programs to assist in this area will not only help the student-athletes, but it can protect the brand of the university and its athletic programs. Being proactive in this area will only improve the message the athletic department is sending. In addition, coaches have the ability to influence the student-athlete into making the proper judgment when using social media, and this could help reinforce the importance of the school's brand.

Sport management scholars should carry out research on the college athlete. Once college athletes receive social media training at their institution, scholars could examine their social media accounts. In addition to monitoring college athletes' social media accounts, researchers can survey college athletes about their usage 
and whether they believe the social media training was effective. This will provide both scholars and practitioners with a baseline for understanding the effectiveness of their trainings.

One further area of investigation for communication scholars may center on journalistic practices. Ulanoff (2013) raised the point that the media is no longer able to police the veracity of its own content. That point remains debatable; however, a larger issue could emerge with journalists and liabilities if they fail to properly vet sources and accounts. Whatever direction future scholarship takes, there are multiple avenues that are ripe for exploration within the realms of catfishing and the creation of fake online personas.

\section{References}

Abrotsky, J.L. (2013, Jan.). Real 'Lennay Kekua hits TV to discuss Manti Te'o hoax. Retrieved from http://www.usatoday.com/story/gameon/2013/01/24/manti-te-o-lennaykekua-diane-o-meara/1860731

Beagle, A.N. (2011). Modern stalking laws: A survey of state anti-stalking statutes considering modern mediums and constitutional challenges, 14 Chap. L. Rev. 457.

Billings v. Atkinson, 489 S.W.2d 858 (Tex. 1973).

Brady, E., \& George, R. (2013, Jan. 18). Manti Te'o's "catfish" story is a common one. Retrieved from http://www.usatoday.com/story/sports/ncaaf/2013/01/17/manti-teoscatfish-story-common/1566438/

Braun v. Flynt, 726 F.2d 245 (5th Cir. 1984).

Burke, T., \& Dickey, J. (2013, Jan. 16). Manti Te'o's dead girlfriend, the most heartbreaking and inspirational story of college football season, is a hoax. Retrieved from http:// deadspin.com/manti-teos-dead-girlfriend-the-most-heartbreaking-an-5976517

Chronicle of Philanthropy. (2013, Jan. 18,). Manti Te'o girlfriend hoax stalls cancer fundraising campaign. Retrieved from https://www.philanthropy.com/article/Manti-TeoGirlfriend-Hoax/218501

Copyright Law of the United States $§ 113$ http://www.copyright.gov/title17/circ92.pdf

Coster, A. (2016, July). AFL players conned by serial catfish posing as top Australian model. Retrieved from http://www.heraldsun.com.au/news/victoria/afl-playersconned-by-serial-catfish-posing-as-top-australian-model/news-story/ff6518b8c59994e4a7648136a6ece887

D'Onfro, J. (2013, October 3). Twitter admits 5\% of its "users" are fake. Retrieved from http://www.businessinsider.com/5-of-twitter-monthly-active-users-are-fake-2013-10

Darlington, J. (2013, Jan. 23). Washington Redskins duped by woman with fake online identity. Retrieved from http://www.nfl.com/news/story/0ap1000000129949/article/ washington-redskins-duped-by-woman-with-fake-online-identity

DelVecchio, S. (2013, Sept. 19). Chris Andersen was catfished. Retrieved from http://larrybrownsports.com/basketball/chris-andersen-catfished/204473

DiVeronica, J. (2014, Sept. 12). One bad tweet can be costly to a student-athlete. Retrieved from http://www.democratandchronicle.com/story/sports/ high-school/2014/09/11/ social-@media-student-athletes-twitter/15473399/

Digital Media Law Project. (2014). Using the name or likeness of another. Retrieved from http://www.dmlp.org/legal-guide/using-name-or-likeness-another

Eddie, R. (2016, July 13). High-profile Australian model's identity stolen and used to catfish at least three AFL players - including one young star whose explicit photos ended up on a U.S. porn site. Retrieved from http://www.dailymail.co.uk/news/article-3688178/ High-profile-Australian-model-s-identity-stolen-used-catfish-three-AFL-playersincluding-one-young-star-explicit-photos-ended-U-S-porn-site.html 
Epstein, T.L. (2012). Regulation of student-athletes' social media use: A guide to avoiding NCAA sanctions and related litigation. Mississippi Sports Law Review, 1(1), 1-36.

ESPN.com. (2013, Jan. 17) Story of Manti Te'o girlfriend a hoax. Retrieved from http:// www.espn.com/college-football/story/_/id/8851033/story-manti-teo-girlfriend-deathapparently-hoax

Federal Education Rights and Privacy Act, 20 U.S. Code $§ 1232 \mathrm{~g}$ (1974). Retrieved from https://www.law.cornell.edu/uscode/text/20/1232g

Federal Education Rights and Privacy Act, Guidance for Eligible Students (2011). Retrieved from http://www2.ed.gov/policy/gen/guid/fpco/ferpa/for-eligible-students.pdf

Fire, M., Kagan, D., Elyashar, A., \& Elovici, Y. (2014). Friend or foe? Fake profile identification in online social networks. Social Network Analysis and Mining, 4(1), 1-23. doi:10.1007/s13278-014-0194-4

Franklin, M.A., \& Bussel, D.J. (1984). The plaintiff's burden in defamation: Awareness and falsity. 25 Wm. \& Mary L. Rev. 825.

Gutman, M., \& Tienabeso, S. (2013, Jan. 21). Timeline of Manti Te'o girlfriend hoax story. Retrieved from http://abcnews.go.com/US/timeline-manti-teo-girlfriend-hoax-story/ story? id $=18268647$

Harris, A. (2013, Jan. 18). Who coined the term "catfish"? Retrieved from http://www.slate. com/blogs/browbeat/2013/01/18/catfish_meaning_and_definition_term_for_online_ hoaxes_has_a_surprisingly.html

Kaplan, A.M., \& Haenlein, M. (2010). Users of the world, unite! The challenges and opportunities of social media. Business Horizons, 53(1), 59-68. doi:10.1016/j. bushor.2009.09.003

Kercheval, B. (2016, Aug. 26). Texas Tech coaches are using fake social media accounts to spy on players. Retrieved from http://www.cbssports.com/college-football/news/texastech-coaches-are-using-fake-social-media-accounts-to-spy-on-players/

Kircher, J.J. (2006). The four faces of tort law: Liability for emotional harm. Marquette Law Review, 90(4/3), 789.

Lavigne, P. (2015, Aug. 27). Police: Bills' IK Enemkpali involved in 2011 catfishing-type incident. Retrieved from http://abcnews.go.com/Sports/police-bills-ik-enemkpaliinvolved-2011-catfishing-type/story?id=33345674

Morrison, K. (2014, April 21). Fake social media accounts incite police investigations. Retrieved from http://www.adweek.com/socialtimes/fake-social-media-accounts-incitepolice-investigations/148176

Nolan, M.P. (2015). Learning to circumvent the limitations of the written-self: The rhetorical benefits of poetic fragmentation and Internet "catfishing." Personal Studies, 1, 53-64.

O'Connor, K.W., Schmidt, G.B., \& Drouin, M. (2016). Helping workers understand and follow social media policies. Business Horizons, 59(2), 205-211. doi:10.1016/j. bushor.2015.11.005

Parker, J. (2016, Aug. 26). Texas Tech coaches try to catfish own players on social media. Retrieved from http://fansided.com/2016/08/26/texas-tech-coaches-try-catfish-playerssocial-media/

Podgor, E.S. (1999). Criminal fraud. American University Law Review, 48(4), 729-768.

Reimer, A. (2015, Aug. 26). IK Enemkpali reportedly once punched a man who posed as a woman and offered sexual favors. Retrieved from http://www.sbnation.com/ nfl/2015/8/26/9213577/ik-enemkpali-punch-police-report-college

Safko, L., \& Brake, D.K. (2009). The social media bible: Tactics, tools and strategies for business success. New York: Wiley.

Sanderson, J. (2011). To tweet or not to tweet: Exploring Division I athletic departments' social media policies. International Journal of Sport Communication, 4(4), 492-513. doi:10.1123/ijsc.4.4.492

Sanderson, J., \& Browning, B. (2013). Training versus monitoring: A qualitative examination of athletic department practices regarding student-athletes and Twitter. Qualitative 
Research Reports in Communication, 14(1), 105-111. doi:10.1080/17459435.2013.8 35348

Sanderson, J., Browning, B., \& Schmittel, A. (2015). Education on the digital terrain: A case study exploring college athletes' perceptions of social media education. International Journal of Sport Communication, 8(1), 103-124. doi:10.1123/IJSC.2014-0063

Sanderson, J., Snyder, E., Hull, D., \& Gramlich, K. (2015). Social media policies within NCAA member institutions: Evolving technology and its impact on policy. Journal of Issues in Intercollegiate Athletics, 8, 50-73.

Schroeder, G. (2013, March 7). How colleges try to keep athletes off the "catfish" hook. Retrieved from http://www.usatoday.com/story/sports/college/2013/03/06/catfishingmichigan-arkansas-manti-teo/1969005/

Scott v. Texas, Nos. PD-1069-09 \& PD-1070-09. (2010). Retrieved from http://caselaw. findlaw.com/tx-court-of-criminal-appeals/1540260.html

Texas penal code $\S 33.07$. Offenses against property of 2009. Retrieved from http://www. statutes.legis.state.tx.us/Docs/PE/htm/PE.33.htm\#33.07

Topheavy Studios, Inc. v. Doe, No. 03-05-00022-CV, 2005 WL 1940159, at*5 (Tex. Ct. App. Aug. 11, 2005)

Tuten, T.L., \& Solomon, M.R. (2013). Social media marketing. Saddle River, NJ: Pearson Publication.

Ulanoff, L. (2013, Jan. 17). The Manti Te'o lesson: We are all catfish. Retrieved from http:// www.mashable.com/2013/01/17/manti-teo-we-are-all-catfish/\#6w4itF.6kqw

Weber, J. (2016, Aug. 24). How a GIF of Aly Raisman's floor routine got me permanently banned from Twitter. Retrieved from https://www.linkedin.com/pulse/how-gif-alyraismans-floor-routine-got-me-permanently-jim-weber

Witherspoon, T. (2016, Feb. 26). Waco judge rules Texas online impersonation law unconstitutional, violates First Amendment. Retrieved from http://www.wacotrib.com/news/ courts_and_trials/waco-judge-rules-texas-online-impersonation-law-unconstitutionalviolates-first/article_d633811c-86d0-5dce-a3f5-924ff6591ba0.html

Wood v. Hustler Magazine, Inc., 736 F.2d 1084 (5th Cir. 1984).

Zimmerman et al. v. Board of Trustees of Ball State University et al., 1:12-cv-01475-JMSDML (Ind. 2013). 